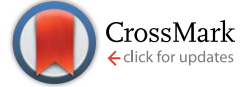

Cite this: RSC Adv., 2017, 7, 14088

Received 11th January 2017

Accepted 21st February 2017

DOI: $10.1039 / \mathrm{c} 7 \mathrm{ra00418d}$

rsc.li/rsc-advances

\section{Polypeptide-participating complex nanoparticles with improved salt-tolerance as excellent candidates for intelligent insulin delivery $\dagger$}

\author{
Yuqiang Li, ${ }^{a}$ Yunyan Zhang, ${ }^{a}$ Junjiao Yang ${ }^{b}$ and Jing Yang*a
}

A facile strategy toward improving the salt-tolerance of a glucose-responsive delivery system to realize selfregulated release of insulin in a physiological environment $(0.15 \mathrm{M}$ phosphate buffer solution, $\mathrm{pH} 7.4$ and 37 ${ }^{\circ} \mathrm{C}$ ) is reported in this study. A type of glucose-responsive complex nanoparticle (CNP) is fabricated by coassembly of two types of amphiphilic copolymers, poly(ethylene glycol)-block-poly(2-phenylboronic ester-1,3-dioxane-5-ethyl)methylacrylate (MPEG-b-PPBDEMA) and poly(ethylene glycol)-block-poly $(\gamma$ benzyl-L-gluamate) (MPEG-b-PBLG). With the help of circular dichroism (CD) and FTIR, it is found that the highly ordered structures ( $\alpha$-helix and $\beta$-sheet) affected the stability of CNPs in $0.15 \mathrm{M}$ salt concentration. The CNPs with 75\% weight fraction of MPEG-b-PBLG exhibit self-regulated release of insulin in response to changes in the glucose concentration under physiological conditions, enabling the repeated on-off release of insulin regulated by normoglycemic and hyperglycemic levels. The probable mechanism of the controllable responsiveness is reasonably deduced based on an investigation of the change of the secondary structure of CNPs during the process of insulin release.

\section{Introduction}

Diabetes mellitus has become one of the most serious threats to human health worldwide. ${ }^{\mathbf{1 , 2}}$ Although daily injection of insulin is by far the most effective way to treat insulin-dependent diabetes mellitus, it brings long-suffering pain and inconvenience to diabetic patients. Recently, great efforts have been devoted to exploring glucose-responsive materials for controlled closedloop insulin delivery systems like mimicking pancreatic function, which can automatically "secrete" insulin in response to the fluctuation of blood glucose concentration. ${ }^{3-5}$ Amongst these self-regulated insulin delivery systems, synthetic phenylboronic acid (PBA)-based polymeric materials with high stability have shown more promising applications than glucose oxidase (GOD) and lectin (Con A) based systems. ${ }^{6-8}$ Until now, a variety of PBA-based glucose-responsive materials particularly in the form of nanoparticles including nanogels (microgels), ${ }^{\mathbf{9 - 1 1}}$ micelles, ${ }^{\mathbf{1 2 - 1 5}}$ vesicles, ${ }^{\mathbf{1 6 - 2 0}}$ and mesoporous silica nanoparticles $^{\mathbf{2 1 , 2 2}}$ have been broadly explored and shown to exhibit effective glucose-responsiveness at physiological $\mathrm{pH}$ and reasonable glucose-sensitivity.

${ }^{a}$ State Key Laboratory of Chemical Resource Engineering, Beijing Key Laboratory of Bioprocess, College of Life Science and Technology, Beijing University of Chemical Technology, Beijing 100029, China. E-mail: yangj@mail.buct.edu.cn

${ }^{b}$ College of Science, Beijing University of Chemical Technology, Beijing 100029, China $\dagger$ Electronic supplementary information (ESI) available. See DOI: 10.1039/c7ra00418d
Besides the controlled glucose-responsiveness at physiological $\mathrm{pH}$ which is the main concern in the current research, another important issue in designing drug carriers for biomedical applications is their stability in physiological environment, particularly salt-tolerance of the drug carriers prior to their glucose-responsiveness. Although a series of PBA-based nanoparticles exhibited controlled glucose-responsive release of insulin under physiological $\mathrm{pH},{ }^{23-40}$ these nanocarriers with relatively low salt stability would undergo the direct disassembly at physiological salt concentration $[0.15 \mathrm{M}$ phosphate buffer solution (PBS)] and release the encapsulated cargo in the absence of sugar molecules. ${ }^{37-42}$ Such requirement of low salt concentration would significantly prevent further investigation of these nanocarriers as potential candidates for smart release of insulin under physiological salt environment.

Synthetic polypeptides have drawn increasing attention as building blocks for construction of nanomaterials, ${ }^{43}$ and been widely studied for various biomedical applications including drug delivery, biosensors and diagnostics, ${ }^{\mathbf{4 4 - 4 9}}$ due to their excellent biocompatibility and biodegradability. For example, copolymers containing a polypeptide backbone and PBA as pendant groups have been prepared to study glucose-dependent insulin release behavior at physiological pH. Chen and his coworkers reported the preparation of a glucose-responsive polymeric micelles using monomethoxy poly(ethylene glycol)- $b$-poly(L-glutamic acid- $c o-N-3-$ L-glutamyl amidophenyl boronic acid). ${ }^{50}$ Shi's group developed a glucose-responsive core-shell-corona micelles through coassembly of two amphiphilic copolymers containing poly(aspartic acid-co-aspartamido phenylboronic acid) block, and 
reported the insulin release behavior at $0.05 \mathrm{M}$ PBS with varying glucose concentrations. ${ }^{51}$ Lately, Shi and his coworkers further studied the glucose-sensitivity of nanoparticles formed from poly( $N$-isopropylacrylamide)-block-poly(aspartic acid-co-aspart amido phenylboronic acid)/poly(aspartic acid-co-aspartamido glucose)-block-poly(ethylene glycol). ${ }^{52}$ However, in those cases, it is mainly focused on the impact of the modifiable carboxyl side group of the synthetic polypeptides on the glucose-responsiveness and biocompatibility of the overall materials.

Compared to traditional amphiphilic copolymers, the synthetic polypeptides usually have more complex and specific molecular interactions in addition to nonspecific hydrophobic interaction. ${ }^{53,54}$ In particular, the molecular hydrogen-bonding interactions would construct the unique higher-ordered structures of polypeptides, which significantly enhanced the stability of polypeptide under the physiological conditions. In fact, synthetic polypeptides have been utilized as tools to mimic hierarchical ordered structures of proteins, providing beneficial information for rational design of materials with proteinmimicking properties. ${ }^{55}$ Understanding the importance of rigidly ordered structures of synthetic polypeptides in physiological environment would intrigue us to design the biomaterials for better satisfying actual need. To the best of our knowledge, few were reported on the secondary structures of synthetic polypeptides impacting on the salt-tolerance of PBAbased nanocarriers under the physiological conditions.

The co-assembly of amphiphilic copolymers is one highly efficient and convenient method to obtain the nanoparticles with the special properties from the individual copolymer. The self-assembled complex nanoparticles (CNP) with hierarchical structures have boosted further achievements in understanding natural self-assembly as well as biomedical applications over the past decade. ${ }^{56,57}$ In this study, we design a kind of CNP by coassembly of two amphiphilic copolymers, poly(ethylene glycol)block-poly $(\gamma$-benzyl-L-gluamate) (MPEG- $b$-PBLG) and poly(ethylene glycol)-block-poly(2-phenylboronate ester-1,3-dioxane5-ethyl)methylacrylate (MPEG- $b$-PPBDEMA) (Scheme 1). The hierarchical PBLG blocks and hydrophobic PPBDEMA blocks from these two copolymers would associate as the core with inherent secondary structure of polypeptide and glucose-

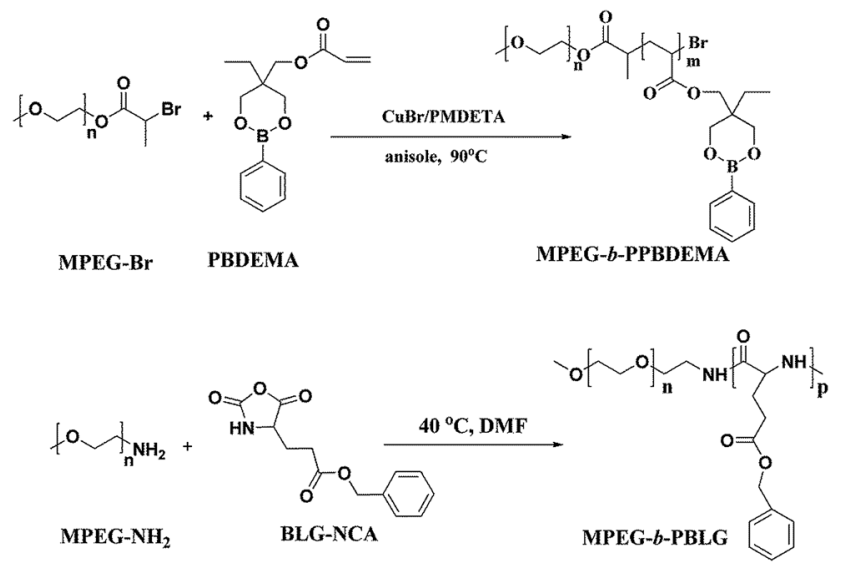

Scheme 1 Synthesis routes of the amphiphilic copolymers. responsiveness under physiological $\mathrm{pH}$. On the basis of hydrophobic interactions of PBLG and PPBDEMA blocks, the hydrophobic core was sturdily strengthened by higher-ordered structure of polypeptide blocks due to molecular hydrogen bonding, which significantly enhanced salt-tolerance of these CNPs. By adjusting the weight ratio between PBLG and PPBDEMA ( $W_{\text {PBLG }} / W_{\text {PPBDEMA }}$ ) in the core, such CNP exhibited exciting stability under normal physiological conditions $(0.15 \mathrm{M}$ PBS and pH 7.4), and had great disparity in glucose-responsive behavior between normoglycemic and hyperglycemic condition. This strategy of introducing synthetic polypeptides with hierarchical ordered structures into glucose-responsive materials may make exploring insulin intelligent administration better match actual requirement.

\section{Experimental section}

\section{Materials}

$\alpha$-Methoxy- $\omega$-amino poly(ethylene glycol) $\left(\right.$ MPEG- $\left.\mathrm{NH}_{2}\right)\left(M_{\mathrm{n}}=5000\right.$, degree of polymerization (DP) $=114$ and polydispersity index (PDI) $=1.05)$ was purchased from Fluka. Monomers (2-phenylboronic esters-1,3-dioxane-5-methyl)methylacrylate (PBDEMA), ${ }^{38} \gamma$-benzylL-gluamate $\mathrm{N}$-carboxyanhydride (BLG-NCA) ${ }^{58}$ and macroinitiator monomethoxy poly(ethylene glycol)-Br (MPEG-Br, $\left.M_{\mathrm{n}}=5100\right)^{37}$ were synthesized according to the reported procedure. Insulin (27 UI $\mathrm{mg}^{-1}$ ) purchased from Genview was labeled by fluorescein isothiocyanate (FITC) based on the previous report. ${ }^{59}$ Anisole was dried with sodium using benzophenone as an indicator. Anhydrous $N, N$-dimethylformamide (DMF) purchased from Aldrich was used without any treatment. All other reagents with analytical grade were used without further purification unless otherwise stated. NIH 3T3 mouse fibroblast cells were provided by Beijing Tumor Resource Institute. DMEM (Dulbecco's Modified Eagle Medium), fetal bovine serum, penicillin and streptomycin purchased from Aldrich were used without treatment.

\section{Characterization}

The chemical structures of the monomeres and copolymers were characterized by ${ }^{1} \mathrm{H}$ NMR carrying out on a $400 \mathrm{MHz}$ NMR instrument (Bruker Corporation, Germany) at room temperature using $\mathrm{CDCl}_{3}$ as solvent. The chemical shifts were measured against the solvent signal of $\mathrm{CDCl}_{3}$ as internal standard. GPC measurements of the block polymers were carried out by Waters 515-2410 instrument equipped with a differential refractive-index detector. The measurements were performed using THF as eluent (flow rate of $1.0 \mathrm{~mL} \min ^{-1}$ at $30{ }^{\circ} \mathrm{C}$ ), and polystyrene standards were employed for calibration. A Hitachi F-4600 Fluorescence instrument (Hitachi High-Technologies Corporation, Tokyo Japan) was used to measure the steady-state fluorescence emission. Laser scattering measurements were performed at $660 \mathrm{~nm}$ by using a laser light scattering spectrometer (ZEN3600, Malvern) with Zetasizer software. TEM was performed on a Hitachi H800 electron microscopy (TEM) operated with $100 \mathrm{kV}$. FTIR measurements were performed on Nicolet 10 with EverGlo light and $\mathrm{KBr}$ plate, and the scanning wavelength was ranged between 4000 and $400 \mathrm{~cm}^{-1}$. Circular dichroism (CD) measurements were 
performed on a Jasco J-810 CD spectropolarimeter at $25{ }^{\circ} \mathrm{C}$ with a cell length of $0.1 \mathrm{~cm}$. The scanning speed was $50 \mathrm{~nm} \mathrm{~min}{ }^{-1}$, and wavelength range was between 260 and $190 \mathrm{~nm}$.

\section{Synthesis of MPEG- $b$-PPBDEMA (P-1)}

The preparation procedure was similar to our previously reported method..$^{37}$ Briefly, a Schlenk flask charged with $\mathrm{CuBr}(5.45 \mathrm{mg}$, $0.038 \mathrm{mmol}$ ), MPEG-Br (196.7 mg, $0.038 \mathrm{mmol}$ ) and $\mathrm{CuBr}_{2}$ (0.43 $\mathrm{mg}, 0.002 \mathrm{mmol}$ ) was degassed using three vacuumnitrogen cycles, followed by adding PMDETA $(7.8 \mathrm{mg}, 0.045$ mmol), monomer PBDEMA (2.1 g, $7.6 \mathrm{mmol})$ and anisole $(1.0 \mathrm{~mL})$ by syringes under nitrogen atmosphere. The reaction system further degassed using three freeze-pump-thaw cycles was immersed in an oil bath at $90{ }^{\circ} \mathrm{C}$ under thermostat control for $40 \mathrm{~h}$. The cooled reaction solution was diluted with $\mathrm{CHCl}_{3}$ and passed through a neutral alumina column to remove the catalyst. The concentrated reaction solution was dropwise added into the mixed solvent of hexane/diethyl ether ( $/ / \mathrm{v}=4 / 1)$, and $1.1 \mathrm{~g}$ product was afforded in yield of $48.3 \% .{ }^{1} \mathrm{H} \mathrm{NMR}\left(400 \mathrm{MHz}, \mathrm{CDCl}_{3}\right)$ $\delta$ (ppm): for PPBDEMA block: $7.75\left(\mathrm{~d}, J=8 \mathrm{~Hz}, 2 \mathrm{H}, o-\mathrm{C}_{6} \mathrm{H}_{5}\right), 7.37$ $\left(\mathrm{m}, 1 \mathrm{H}, p-\mathrm{C}_{6} \mathrm{H}_{5}\right), 7.29\left(\mathrm{~m}, 2 \mathrm{H}, m-\mathrm{C}_{6} \mathrm{H}_{5}\right), 3.76-3.99\left(\mathrm{~m}, 6 \mathrm{H}, \mathrm{CH}_{2} \mathrm{OOC}\right.$, $\mathrm{CH}_{2} \mathrm{OBOCH}_{2}$ and $\mathrm{CH}_{2} \mathrm{OBOCH}_{2}$ ), 2.29 (br, $1 \mathrm{H}, \mathrm{CHCH}_{2}$ ), 1.60-1.91 (br, $2 \mathrm{H}, \mathrm{CHCH}_{2}$ ), $1.35\left(\mathrm{~m}, 2 \mathrm{H}, \mathrm{CH}_{2} \mathrm{CH}_{3}\right), 0.79\left(\mathrm{~m}, 3 \mathrm{H}, \mathrm{CH}_{2} \mathrm{CH}_{3}\right)$; for MPEG block: 3.64 (s, $\left.4 \mathrm{H}, \mathrm{CH}_{2} \mathrm{CH}_{2} \mathrm{O}\right), 3.38$ (s, $\left.3 \mathrm{H}, \mathrm{CH}_{3} \mathrm{O}\right)$.

\section{Synthesis of MPEG- $b$-PBLG (P-2)}

MPEG-NH $\mathrm{N}_{2}(0.5 \mathrm{~g}, 0.1 \mathrm{mmol}), \mathrm{BLG}-\mathrm{NCA}(0.79 \mathrm{~g}, 3.0 \mathrm{mmol})$ and $2.0 \mathrm{~mL}$ anhydrous DMF were added into $25 \mathrm{~mL}$ Schlenk flask in the glovebox. The reaction mixture was stirred at $40{ }^{\circ} \mathrm{C}$ for $3 \mathrm{~d}$, and the resulting solution was precipitated into 10 -fold excess of cold diethyl ether. The crude solid was washed twice with diethyl ether to obtain $1.08 \mathrm{~g}$ of white solid in yield of $83.5 \% .{ }^{1} \mathrm{H}$ NMR (400 MHz, $\mathrm{CDCl}_{3}$ ), $\delta(\mathrm{ppm}): 7.89(1 \mathrm{H},-\mathrm{NH}-), 7.41-7.16$ $\left(5 \mathrm{H}, \mathrm{C}_{6} \mathrm{H}_{5}-\right), 5.13-5.09\left(2 \mathrm{H},-\mathrm{CH}_{2}-\mathrm{C}_{6} \mathrm{H}_{5}\right), 4.62(1 \mathrm{H},-\mathrm{CO}-\mathrm{CH}-$ $\mathrm{NH}-), 3.95-3.68$ (- $\left.\mathrm{CH}_{2} \mathrm{CH}_{2} \mathrm{O}-\right), 2.46\left(2 \mathrm{H}, \mathrm{BnO}-\mathrm{CO}-\mathrm{CH}_{2}-\right), 2.13-$ $1.93\left(2 \mathrm{H},-\mathrm{CH}_{2}-\mathrm{CH}-\right)$.

\section{Preparation and characterization of CNP}

$10 \mathrm{mg}$ mixture of two block polymers with six different P-2 weight fraction including $0,10 \%, 30 \%, 50 \%, 75 \%, 100 \%$ were dissolved in $1.0 \mathrm{~mL}$ THF, respectively. CNPs were carried out by slowly adding the mixed polymer solutions into $10 \mathrm{~mL}$ ultrapure water, followed by the evaporation of THF with stirring. The nanoparticles solution was dialyzed against ultrapure water in a dialysis bag with a molecular weight cutoff of 3500 for $48 \mathrm{~h}$, during which dialysis water was refreshed every $6 \mathrm{~h}$. The concentrations of the resulting CNP were all fixed at $1.0 \mathrm{mg} \mathrm{mL} \mathrm{mL}^{-1}$.

The secondary structure of CNP aqueous solution was determined by CD measurement. The CNP solutions with different P-2 content at $0.2 \mathrm{mg} \mathrm{mL}^{-1}$ were scanned from 190 to $260 \mathrm{~nm}$, and accumulated 5 times at a resolution of $1.0 \mathrm{~nm}$ and scanning speed of $700 \mathrm{~nm} \mathrm{~min}^{-1}$. The secondary structure population was calculated using software CD Pro. After CNP solution was lyophilized, the freshly-ground mixture of $2.0 \mathrm{mg}$ CNPs and $110 \mathrm{mg}$ anhydrous $\mathrm{KBr}$ was used for FTIR measurements.

\section{FITC-insulin loading and entrapment capacity evaluation of CNPs}

Firstly, a stock of FITC-insulin $(3.0 \mathrm{mg})$ dissolved in $10 \mathrm{~mL} \mathrm{HCl}$ $(0.01 \mathrm{M})$ was adjusted to $\mathrm{pH} 6.0$ using $\mathrm{NaOH}(0.1 \mathrm{M})$. Subsequently, $10 \mathrm{mg} \mathrm{mL}^{-1}$ mixture of two block polymers with the given weight ratio of P-2 in THF was dropwise added into the above mentioned FITC-insulin aqueous solution with stirring in ice bath. After THF evaporation, the purification of CNPS encapsulating FITC-insulin was performed by dialysis method (MWCO, $14000 \mathrm{Da}$ ). The encapsulated insulin mass was calibrated according to the measured standard curve of fluorescence intensity against insulin concentration. The insulin entrapment efficiency (EE) and loading capacity (LC) were calculated using the following equations:

$$
\begin{aligned}
& \mathrm{EE} \%=\frac{\text { encapsulated insulin }}{\text { total insulin }} \times 100 \\
& \mathrm{LC} \%=\frac{\text { encapsulated insulin }}{\mathrm{NP} \text { weight }} \times 100
\end{aligned}
$$

\section{Salt-tolerance of CNPs}

The release of FITC-insulin from CNPs under the stimuli of different salt concentrations $(0.01,0.03,0.05,0.10$ and $0.15 \mathrm{M}$ PBS) was used to evaluate their salt stability. The release of insulin was carried out by dialysis. The dialysis bag with a molecular weight cutoff $14 \mathrm{kD}$ filled with $1.0 \mathrm{mg} \mathrm{mL}^{-1}$ of purified insulin-encapsulated CNPs were immersed in $40 \mathrm{~mL}$ of the given PBS concentrations $(\mathrm{pH}=7.4)$ at $37^{\circ} \mathrm{C}$. The cumulative released FTIC-insulin outside of the dialysis bag was assayed by fluorescence spectrometry at an emission wavelength of $525 \mathrm{~nm}$ upon excitation at $494 \mathrm{~nm}$.

\section{Glucose-responsive release}

Based on the results of salt stability, CNPs with 50\% and 75\% weight fractions of $\mathrm{P}-2$ were selected to investigate insulin release behavior with varying glucose concentrations of $0,1.0$, 2.0 and $3.0 \mathrm{mg} \mathrm{mL}^{-1}$ at $0.15 \mathrm{M}$ PBS, pH 7.4 and $37^{\circ} \mathrm{C}$. Other operations were similar to the salt stability.

The insulin release by pulsed triggering of glucose concentration was performed by immersing drug-loaded CNPs alternatively in 1.0 and $5.0 \mathrm{mg} \mathrm{mL} \mathrm{mL}^{-1}$ glucose for $9 \mathrm{~h}$ under physiological condition ( $0.15 \mathrm{M}$ PBS, pH 7.4 and $37^{\circ} \mathrm{C}$ ), and the release percentage of insulin was monitored by fluorescence spectrometry every $3 \mathrm{~h}$.

\section{In vitro cytotoxicity of the nanoparticles}

The in vitro cytotoxicity was evaluated by MTS assay (Cell Titer 96 Aqueous One Solution Cell Proliferation assay). NIH3T3 mouse fibroblast cells were cultured in monolayer in DMEM (Dulbecco's Modified Eagle Medium) supplemented with 10\% fetal bovine serum, $1 \%$ penicillin/streptomycin in $5 \% \mathrm{CO}_{2} / 95 \%$ air at $37{ }^{\circ} \mathrm{C}$. The cells were seeded into a 96-well plate at a density of $1.0 \times 10^{4}$ cells per well. The prepared CNP solutions were diluted to give a range of final concentration from 25 to $500 \mathrm{mg} \mathrm{L}^{-1}$ using DMEM solutions. The plates were maintained 
in the incubator for 24,48 and $72 \mathrm{~h}$, respectively. After incubation, $20 \mu \mathrm{L}$ of MTS solution was added to each well. After the predetermined incubation time, $20 \mu \mathrm{L}$ of MTS was added into each well and incubated for a further $2 \mathrm{~h}$. The optical density of the solution was measured at $490 \mathrm{~nm}$ using a microplate reader (Labsystem, Multiskan, Ascent, Finland) in triplicate. The relative cell proliferation was calculated as the percentage of cell viability as compared with that of an untreated control.

\section{Results and discussion}

\section{Synthesis and characterization of two amphiphilic block copolymers}

The amphiphilic copolymers MPEG- $b$-PPBDEMA (P-1) and MPEG- $b$-PBLG (P-2) were respectively synthesized by atom transfer radical polymerization (ATRP) ${ }^{37}$ and ring-opening polymerization (ROP) as reported ${ }^{52}$ (Scheme 1). The chemical structures of the block copolymers P-1 and P-2 were confirmed by ${ }^{1} \mathrm{H}$ NMR and GPC measurements. From ${ }^{1} \mathrm{H}$ NMR results shown in Fig. S1 and $\mathrm{S} 2, \uparrow$ the degree of polymerization (DP) of PPBDEMA and PBLG blocks in these copolymers, comparing the peak intensities between the phenyl protons of PPBDEMA $(\delta$ $=7.78 \mathrm{ppm})$ or methylene of PBLG block $(\delta=5.07 \mathrm{ppm})$ and the methyl protons of MPEG block $(\delta=3.43 \mathrm{ppm})$, were calculated to be 75 and 20, respectively (Table 1). GPC measurements exhibited unimodal and relatively narrow distribution without macroinitiator MPEG-Br or MPEG-NH $\mathrm{N}_{2}$ (Fig. S3 and $\mathrm{S} 4 \dagger$ ), further indicating the successful preparation of these copolymers. Using fluorescence technique with pyrene as probe, critical micellar concentrations (CMC) of P-1 and P-2 were measured to be 9.8 and $2.4 \mathrm{mg} \mathrm{L}^{-1}$ (Fig. S5 $\dagger$ ). The low and close CMCs suggested that these two copolymers had similar and strong hydrophobic aggregation force, which provided great opportunity to form CNPs instead of two single nanoparticles self-assembled by individual copolymer in aqueous solution.

\section{Fabrication of complex nanoparticles (CNP)}

To obtain glucose-responsive CNPs, four different CNPs with varying weight ratios of P-2 were fabricated through simple co-assembly of P-1 and P-2, in which the contents of P-2 in CNPs were respectively $10 \%, 30 \%, 50 \%$ and $75 \%$. TEM technology was employed to study the nanostructures of the CNPs as related to the P-2 composition ratio. TEM image of the CNPs with 30\% content of P-2 showed closely spherical micelles with the average diameter of $40 \mathrm{~nm}$ (Fig. S6A $\dagger$ ). With increasing P-2 weight fraction in CNPs to 50\% (Fig. S6B $\dagger$ ) and 75\% (Fig. 1A), the polymeric vesicles with outer diameter of $30 \mathrm{~nm}$ and wall thickness of $5 \mathrm{~nm}$ were interestingly observed. DLS measurement was performed to investigate the size and distribution of the nanoparticles via co-assembly of the two copolymers in aqueous solution. As shown in Fig. 1B, the sizes of CNPs with P2 content ranged from $10-75 \%$ were below $50 \mathrm{~nm}$ at $\mathrm{pH} 7.4$ and $25{ }^{\circ} \mathrm{C}$. Compared to the single nanoparticles formed from P-1, the average diameters of CNPs were slightly decreased with an increase of P-2 weight ratio in the whole nanoparticles, which is possibly associated with the shorter chain length of hydrophobic PBLG block. The relatively narrow PDI of CNPs suggested the successful formation of complex nanoparticles by coassembly.

\section{Secondary structure analysis}

CD spectroscopy is one of the most convenient ways to estimate the secondary structures of proteins. Therefore, the secondary structures of CNPs with varying P-2 weight ratio at $0.2 \mathrm{mg} \mathrm{mL}^{-1}$ in water were first examined with CD spectroscopy. It is well known that $\alpha$-helical structure can be characterized by two negative bands at 208 and $222 \mathrm{~nm}$ and a strong positive band about $192 \mathrm{~nm}$, and the $\beta$-sheet structure was characterized by a negative minimum band near $218 \mathrm{~nm}$ and a positive maximum between 185 and $200 \mathrm{~nm} .{ }^{48}$ For the CNPs by co-assembly of P-1 and P-2, Fig. 2A shows the gradual transformation of the $\alpha$ helical conformation was evidenced by the slight change of the ellipticity ratio $\left([\theta]_{222} /[\theta]_{208}\right)$, upon increasing $\mathrm{P}-2$ content from $10 \%$ to $100 \%$. The quantitative analyses of secondary structures were further conducted by employing Spectra software CD Pro. For each CNP, the secondary structure was composed of $\alpha$-helix, $\beta$-sheet and other secondary structures (Fig. 2B), regardless of the difference in the chemical compositions. As the weight fraction of P-2 in CNPs increased from $10 \%$ to $75 \%$, the $\beta$-sheet content decreased systematically from $41.8 \%$ to $15.6 \%$ of total components, and the $\alpha$-helical chains raised gradually from $4.2 \%$ to $36.9 \%$. The $\alpha$-helix contribution to secondary structure became dominant over the $\beta$-sheet contribution with P-2 weight fraction greater than $60 \%$ in CNPs. Other secondary structure percentage was slightly reduced for all formulations.

Freeze-dried complex nanoparticles were further studied by FTIR spectroscopy, and the characteristic absorbance of the secondary structures was clearly observed in Fig. S7.† The

Table 1 Molecular characterization of amphiphilic block polymers

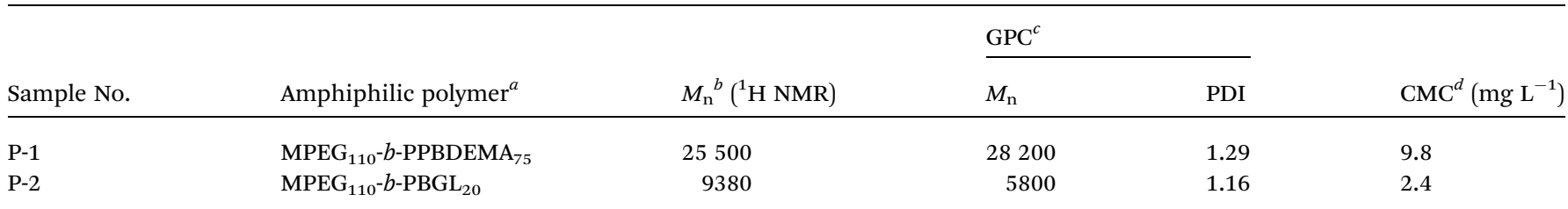

${ }^{a}$ The numbers at the footnote showing the average repeating unit number of each moiety were determined by ${ }^{1} \mathrm{H}$ NMR. ${ }^{b}$ The number-average molecular weights of the block copolymers were calculated from ${ }^{1} \mathrm{H}$ NMR results. ${ }^{c}$ Determined by GPC measurements. ${ }^{d}$ Measured by fluorescence technique using pyrene as probe. 

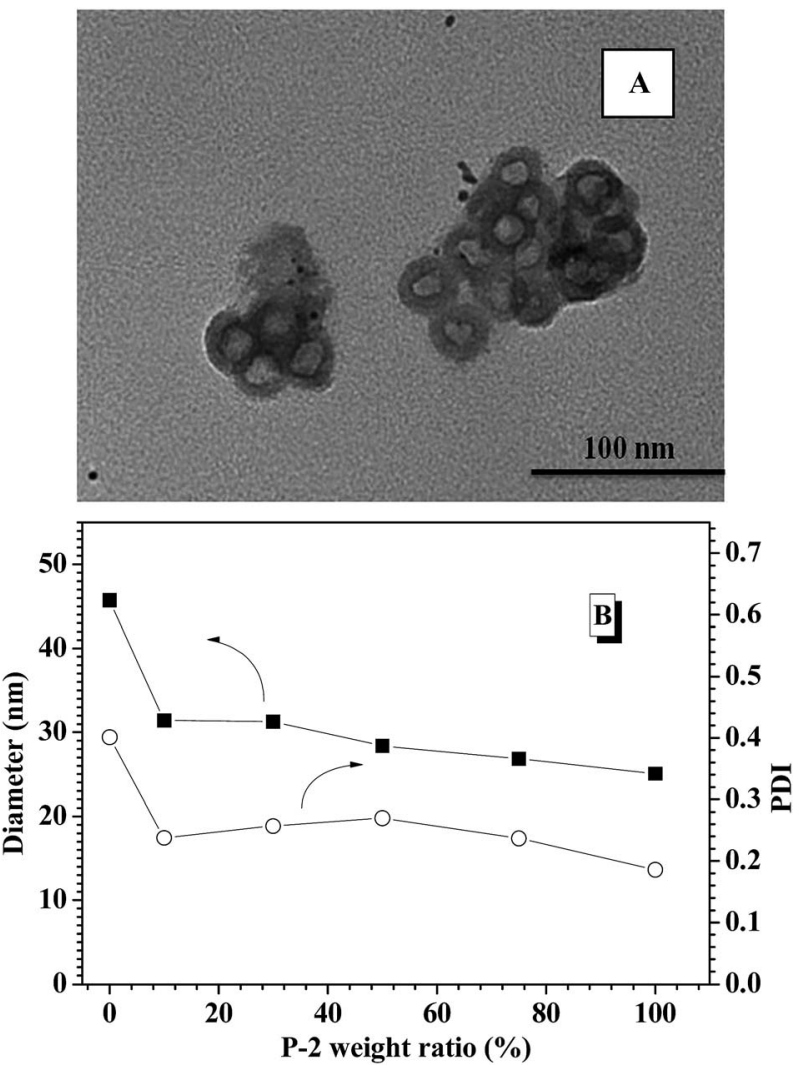

Fig. 1 (A) TEM images of CNPs with 75\% content of $\mathrm{P}-2$; (B) DLS results of polymeric nanoparticles with different $\mathrm{P}-2$ weight ratio.

absorbance at $1653 \mathrm{~cm}^{-1}(\mathrm{C}=\mathrm{O}$ stretching vibration, amide I) and at $1547 \mathrm{~cm}^{-1}(\mathrm{~N}-\mathrm{H} \text { bending vibration, amide } \mathrm{II})^{60}$ were attributed to $\alpha$-helical conformations. Meanwhile, the absorption bands of amide I appeared at $1626 \mathrm{~cm}^{-1}$, indicating the presence of the $\beta$-sheet conformation. ${ }^{61}$ The peak at $1733 \mathrm{~cm}^{-1}$ corresponded to the $\mathrm{C}=\mathrm{O}$ stretch of the benzyl ester group in the side chain of BLG. ${ }^{62}$ Relative to the benzyl ester group at $1733 \mathrm{~cm}^{-1}$, the absorption intensities assigned to the peaks of $\alpha$-helical conformation increased with higher weight fraction of P-2 in the CNPs, which clearly indicates that the secondary structure of the complex nanoparticles went through a change toward more compact $\alpha$-helix conformation.

\section{Effect of P-2 content on salt-tolerance of CNPs}

Prior to intelligent releasing its cargos under special stimuli, the stability of drug delivery systems in normal physiological environment is one important factor to measure their safety for the medical application. Amongst others, the salt tolerance of nanocarriers at physiological concentration (0.15 M PBS) is a major concern. To evaluate the salt-tolerance of the CNPs, in this study, FITC-labeled insulin was encapsulated into the complex nanoparticles by co-assembly of P-1 and P-2 as reported, ${ }^{36}$ and the release behavior of the loaded insulin from the CNPs was tested upon varying salt concentration. As shown in Fig. 3A, although they exhibited nearly zero release of FITCinsulin at the salt concentration of $0.01 \mathrm{M}$ and $37{ }^{\circ} \mathrm{C}$ for $75 \mathrm{~h}$ incubation, one distinct cumulative release of insulin was
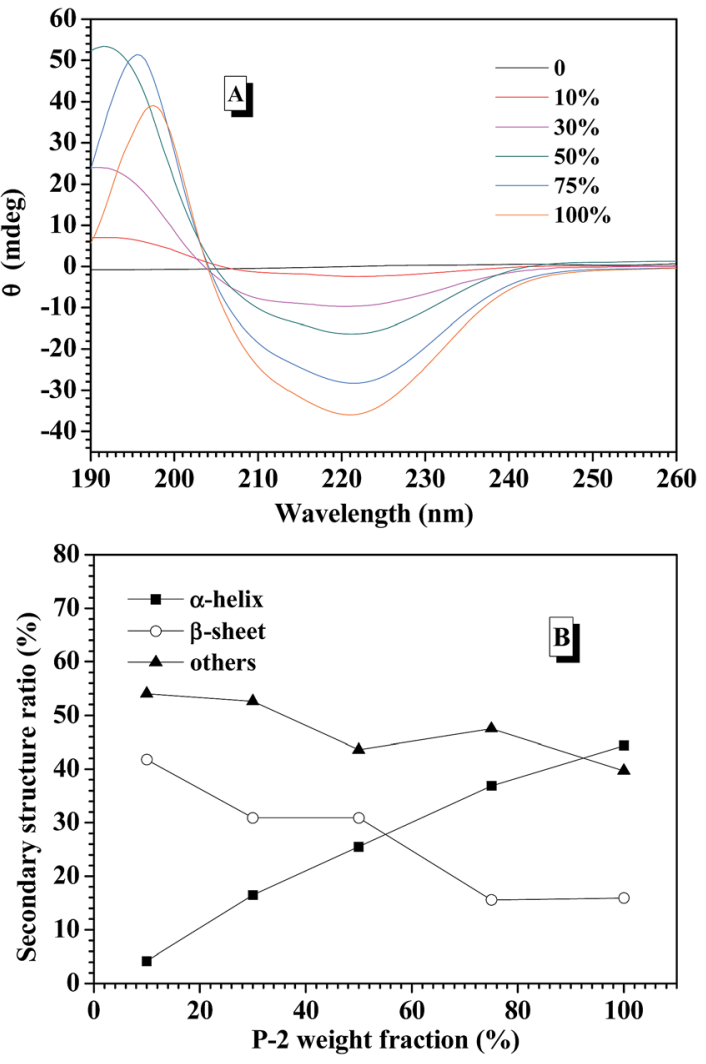

Fig. 2 (A) Circular dichroism spectra of CNPs varying P-2 content in aqueous solution at the concentration of $0.2 \mathrm{mg} \mathrm{mL}^{-1}$. (B) The calculated secondary structure populations of CNPs versus the weight fraction of $\mathrm{P}-2$ in deionized water.

investigated when the salt concentration was slightly increased to $0.03 \mathrm{M}$. Moreover, the release efficiency of insulin was accelerated with increasing salt concentration. Above $0.10 \mathrm{M}$ salt concentration, the cumulative release of insulin rapidly reached $80 \%$ during the first $40 \mathrm{~h}$. These results demonstrated that the nanocarriers from P-1 had low salt-stability and saltdependent responsive release behavior. However, when the nanocarriers were formed via the co-assembly of P-1 and P-2, their salt stability was significantly improved upon an increase of P-2 weight fraction in CNPs. For example, the CNPs with only 10 percentage of P-2 content exhibited better salttolerance than that from P-1 alone. The quite low cumulative release of insulin was monitored at the salt concentration of $0.03 \mathrm{M}$, and the release efficiency was obviously slowed down at $0.05 \mathrm{M}$ (Fig. 3B). When P-2 weight fraction in CNPs was increased to $30 \%$, the low release of insulin from the CNP was detected at salt concentration of $0.05 \mathrm{M}$, and the insulin release was clearly depressed even at $0.15 \mathrm{M}$ (Fig. 3C). With further increasing P-2 weight ratio to $50 \%$ in CNPs, it was excitingly found that the CNPs showed perfect stability in the measured range of salt concentration except the slight release behavior at $0.15 \mathrm{M}$ during $75 \mathrm{~h}$ incubation (Fig. 3D). As P-2 content was enhanced to $75 \%$, the CNPs exhibited high salt stability at $0.15 \mathrm{M}$ (Fig. 3E). The cumulative release of insulin from the CNPs with different P-2 weight fraction at the salt concentration 

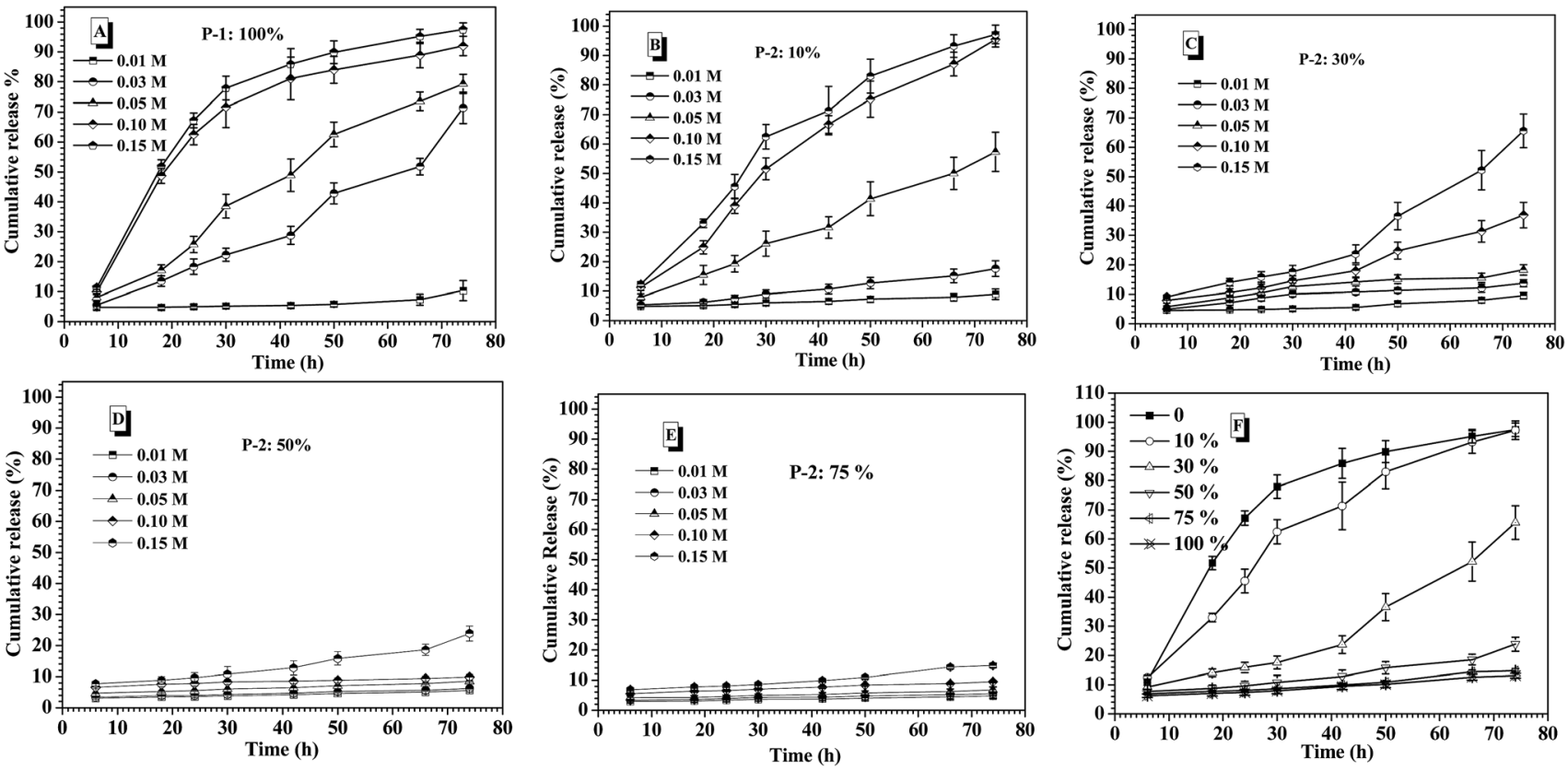

Fig. 3 Salt concentration-dependent release behavior of insulin from the nanoparticles of single $\mathrm{P}-1$ (A); the CNPs with $10 \% \mathrm{P}-2$ content (B); with $30 \%$ P-2 content (C); with $50 \%$ P-2 content (D); with $75 \% \mathrm{P}-2$ content (E) at $\mathrm{pH} 7.4$ and $37^{\circ} \mathrm{C}$. (F) The cumulative release of insulin from CNPs with varying $\mathrm{P}-2$ weight fraction at $0.15 \mathrm{M}$ salt concentration and $37{ }^{\circ} \mathrm{C}$.

of 0.15 $\mathrm{M}$ was further summarized in Fig. 3F. It is clearly seen that with P-2 content increasing systematically from 0 to $75 \%$, the insulin release trend of the complex nanoparticles was gradually decreased, and the cumulative release amount of insulin was finally reduced to less $10 \%$. These results indicate that the introduction of P-2 into the self-assembly system of P-1 can efficiently enhance the stability of the overall nanocarriers in the physiological salt environment, and the salt-tolerance of the resulting CNPs would be adjusted by a change of P-2 weight fraction.

To ascertain the significance of P-2 enhancing the salt stability of CNPs, as control, polyethylene glycol-block-poly(lactic acid) [MPEG5000- $b$-PLA, $M_{\mathrm{n}}\left({ }^{1} \mathrm{H}\right.$ NMR $)=25600$, PDI measured by GPC is 1.35] with biodegradable polyester as hydrophobic block, and polyethylene glycol-block-polystyrene [MPEG5000- $b$-PS, $M_{\mathrm{n}}\left({ }^{1} \mathrm{H}\right.$ NMR $)=9000$, PDI measured by GPC is 1.31] with strong hydrophobic block were respectively prepared, as displayed in Scheme S1. $\dagger$ The new complex nanoparticles were formed via the co-assembly of P-1 and MPEG- $b$-PLA or MPEG- $b$-PS with different weight ratio, respectively. The effect of the different chemical structure and component ratios on the stability of the complex nanoparticles was comparatively investigated at $0.15 \mathrm{M}$ salt concentration. As shown in Fig. S9A, $\dagger$ as an increase of MPEG- $b$-PLA weight fraction in CNPs, the release of insulin was slowed down in some degree. However, the CNPs with $75 \%$ weight fraction of MPEG- $b$-PLA still exhibited $50 \%$ cumulative release amount of insulin for $75 \mathrm{~h}$ incubation. The CNPs formed via the co-assembly of P-1 and MPEG- $b$-PS displayed high cumulative release of insulin at $0.15 \mathrm{M}$ salt concentration, and even CNPs with 75\% weight fraction of MPEG- $b$-PS showed rapid and high release behavior of insulin in the first $30 \mathrm{~h}$ (Fig. S9B $\dagger$ ). Moreover, there was no great disparity in the enhancement of salt stability among different MPEG- $b$-PS contents. Although PLA and PS blocks had strong hydrophobic aggregation, these CNPs maintained by only hydrophobic interaction didn't exhibit satisfying the stability at $0.15 \mathrm{M}$ PBS.

To explore the contribution of P-2 to stabilize the CNPs in the physiological salt environment, the secondary structure change of the CNPs with different P-2 content at $0.15 \mathrm{M}$ salt concentration was carefully investigated by CD measurement. After the CNPs containing the given P-2 content were incubated in $0.15 \mathrm{M}$ salt concentration for $10 \mathrm{~min}$, their CD curves were subsequently collected (Fig. S10A $\dagger$ ). The calculated secondary structure populations of CNPs with different P-2 contents were displayed in Fig. 4A. The change trend of secondary structure in $0.15 \mathrm{M}$ salt concentration was similar to that in deionized water (Fig. 2B). With an increase of P-2 weight fraction in CNPs from $10 \%$ to $75 \%$, the content of $\beta$-sheet conformation decreased from $40.1 \%$ to $14.7 \%$, corresponding to an obvious increase in $\alpha$-helical chains from $4 \%$ to $34.2 \%$. The content of other secondary structure ( $\beta$-turn and random coil) was gradually decreased with P-2 content increasing, indicating the enhancement of the ordered structure in the overall conformation. The more highly ordered structure of CNPs benefits to their stability at physiological salt concentration.

The secondary structure of CNPs with $75 \%$ content of P-2 was further monitored by $\mathrm{CD}$ measurements at $0.15 \mathrm{M}$ salt concentration and $37^{\circ} \mathrm{C}$ for $60 \mathrm{~h}$ incubation. As shown in Fig. 4B, the decrease of $\alpha$-helix content was accompanied by an increase of $\beta$ sheet structure. The sum of $\alpha$-helix and $\beta$-sheet was kept above $50 \%$ of the whole secondary structures during $60 \mathrm{~h}$ incubation. 

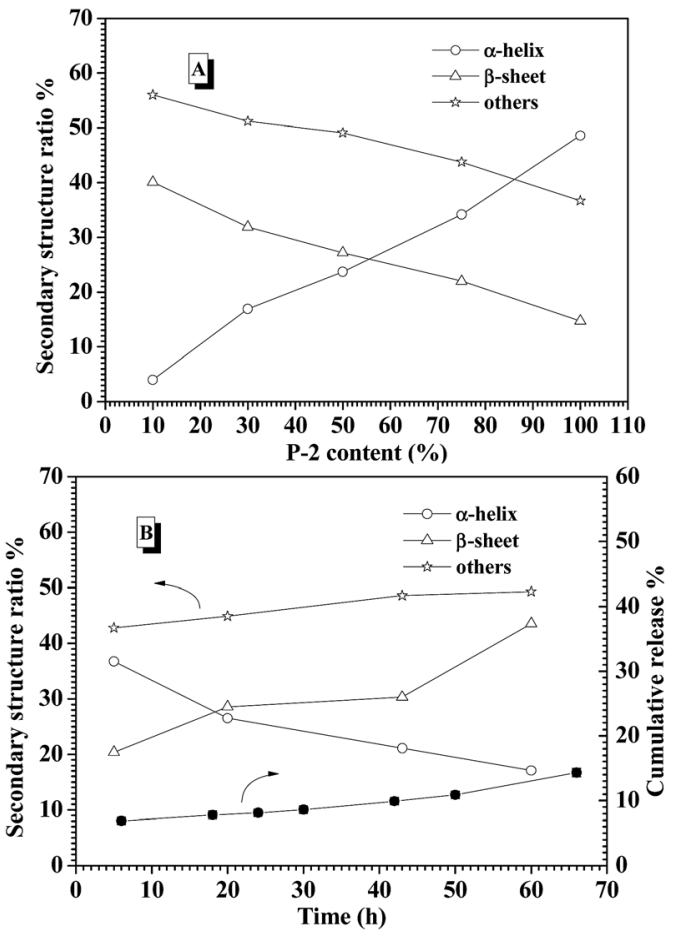

Fig. 4 (A) The calculated secondary structure populations of CNP versus the weight fraction of $\mathrm{P}-2$ at $0.15 \mathrm{M}$ salt concentration. (B) The secondary structure populations change of the CNPs with $75 \%$ content of $\mathrm{P}-2$ at $0.15 \mathrm{M}$ salt concentration and $37^{\circ} \mathrm{C}$ for $60 \mathrm{~h}$.

Meanwhile, it is monitored that the cumulative release of insulin from the CNPs with $75 \%$ of $\mathrm{P}-2$ content was well controlled to be about $10 \%$ in the measured time. This low release of insulin is very likely attributed to the constant content of the highly ordered structure in CNPs.

\section{Insulin-loading of the CNPs}

From the above results, the CNPs with $75 \%$ of P-2 content were selected to investigate the entrapment efficiency (EE) and loading capacity (LC) of FITC-insulin in the CNP's depending on the concentrations of the nanoparticle and FITC-insulin, as shown in Fig. 5. For example, when FITC-insulin concentration was controlled at $0.1 \mathrm{mg} \mathrm{mL}$, EE of insulin was dramatically enhanced from $30 \%$ to $70 \%$ with a change in CNPs' concentration from 0.5 to $1.0 \mathrm{mg} \mathrm{mL}^{-1}$ (Fig. 5A). However, LC leveled off at the CNPs' concentration of $1.0 \mathrm{mg} \mathrm{mL}^{-1}$ and slightly decreased when CNPs' concentration was increased to $1.5 \mathrm{mg} \mathrm{mL}^{-1}$ (Fig. 5B). Although the high nanoparticles' concentration can strengthen the interaction with the loaded molecules, leading to high EE of insulin, the too high nanocarriers' mass would result in LC lowering. When the given insulin concentration was increased from 0.1 to $0.2 \mathrm{mg} \mathrm{mL}^{-1}$, both EE and LC of insulin was simultaneously enhanced, particularly, LC was obviously increased to $12 \%$. However, when the given insulin concentration was further enhanced to $0.3 \mathrm{mg} \mathrm{mL}^{-1}$, EE started to drop off at the CNPs' concentration of 1.0 and $1.5 \mathrm{mg} \mathrm{mL}^{-1}$, and LC was only slightly increased. In contrast to the nanoparticles formed from only P-1, the CNPs exhibited higher EE and LC of insulin in
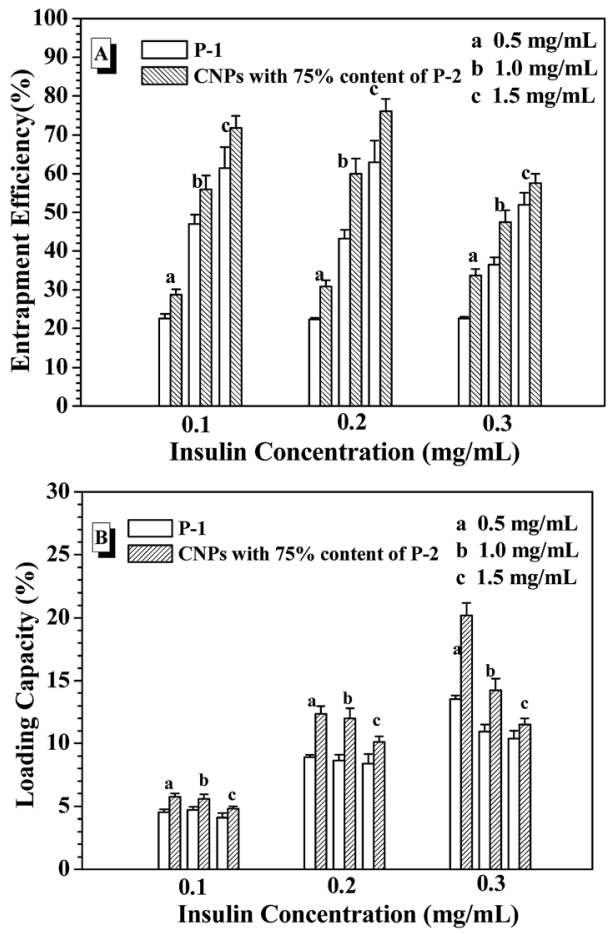

Fig. $5 \mathrm{EE}(\mathrm{A})$ and LC (B) with varying the nanoparticle concentration and the given insulin concentration.

the experimental range. As discussed above, the CNPs' concentration of $1.0 \mathrm{mg} \mathrm{mL}^{-1}$ and the given insulin concentration of $0.2 \mathrm{mg} \mathrm{mL} \mathrm{mas}^{-1}$ walected as the encapsulation condition of insulin for the following glucose-responsiveness.

\section{Glucose-responsive release of FITC-insulin from the CNPs}

In the human body, the normal blood glucose level fluctuates in the range of 0.6 and $1.2 \mathrm{mg} \mathrm{mL} \mathrm{m}^{-1}$. Over $2.0 \mathrm{mg} \mathrm{mL}{ }^{-1}$ glucose concentration is generally considered as hyperglycemia, which needs to be treated. Besides, hypoglycemia effect induced by excess insulin release from the drug carriers under normoglycemia should be strictly avoided, because hypoglycemia happens rapidly and easily threatens the life. In the consideration of the self-regulated insulin release demand upon the change of blood glucose concentration, the glucose-responsiveness of these CNPs by co-assembly of P-1 and P-2 was evaluated under the simulated physiological environment ( $\mathrm{pH} 7.4,0.15 \mathrm{M}$ PBS and $37^{\circ} \mathrm{C}$ ) in this study. The cumulative release of insulin from these nanoparticles was calculated by monitoring the changes in the fluorescence intensity of the external fluid. Fig. 6A shows the insulin release profiles from the CNPs with $50 \%$ P-2 weight fraction upon varying glucose concentration at physiological environment. In the absence of glucose, less $20 \%$ insulin was released from the CNPs for $90 \mathrm{~h}$ measurement, exhibiting good stability of the complex nanoparticles. When the FITC-insulin loaded CNPs was incubated at the glucose concentration of $1.0 \mathrm{mg} \mathrm{mL}^{-1}$ (normoglycemic condition), low release of insulin was observed in the first $60 \mathrm{~h}$, however, the subsequently rapid release led to over $50 \%$ of the insulin escaping from the CNPs after $90 \mathrm{~h}$ incubation. 
Although the CNPs with $50 \%$ of P-2 content exhibited excellent performance of glucose-responsive behavior at glucose concentration of 2.0 and $3.0 \mathrm{mg} \mathrm{mL}^{-1}$, excessive release of insulin at normal physiological condition makes the CNPs with 50\% content of P-2 deviate from the basic demand of insulin delivery systems.

Concurrently, the insulin release from CNPs with $75 \%$ of P-2 content was investigated under the simulated physiological environment, and the exciting results upon varying glucose concentration were shown in Fig. 6B. Due to the increase of P-2 content in CNPs, the remarkable and sustained insulin release was not only observed at a relatively stable release rate under hyperglycemic condition, more importantly, the release of insulin at glucose concentration of $1.0 \mathrm{mg} \mathrm{mL}^{-1}$ was efficiently controlled. During $90 \mathrm{~h}$ measurement, less than $20 \%$ release of insulin demonstrated the better stability of the CNPs with $75 \%$ of P-2 content under normal physiological condition, decreasing the risk of the hypoglycemia occurrence. Besides, the CNPs with $75 \%$ of P-2 content also displayed the faster release of insulin at $3.0 \mathrm{mg} \mathrm{mL}^{-1}$ glucose than $2.0 \mathrm{mg} \mathrm{mL}^{-1}$, indicating that the CNPs had the ability of self-regulated insulin release upon the glucose concentration fluctuation.

Furthermore, the on-off insulin release ability of the CNPs with $75 \%$ weight fraction of P-2 upon the physiological demand was evaluated through the consecutive switch of glucose concentration between 1.0 and $5.0 \mathrm{mg} \mathrm{mL}^{-1}$ every $9 \mathrm{~h}$ at $0.15 \mathrm{M}$ PBS, pH 7.4 and $37^{\circ} \mathrm{C}$ (Fig. 6C). The insulin-loaded CNPs were first placed at physiological solution with $1.0 \mathrm{mg} \mathrm{mL}^{-1}$ glucose, and almost zero release of insulin was observed in the first $9 \mathrm{~h}$. After that, the culture medium was changed to the phosphate buffer with $5.0 \mathrm{mg} \mathrm{mL}{ }^{-1}$ glucose, then, relatively obvious insulin release, $c a$. $4.8 \%$ release amount, was seen for the subsequent $9 \mathrm{~h}$. When the release media was switched back to the physiological solution with $1.0 \mathrm{mg} \mathrm{mL} \mathrm{m}^{-1}$ glucose, insulin release was immediately paused and release plateau was obtained in the following $9 \mathrm{~h}$. Once the release medium was alternated to $5.0 \mathrm{mg} \mathrm{mL}^{-1}$ glucose, the release behaviour of insulin was triggered again, which was demonstrated by release of $5.5 \%$ insulin in the fourth $9 \mathrm{~h}$. Such on-off insulin release was more clearly observed in the next several cycles of alternate glucose concentration between 1.0 and $5.0 \mathrm{mg} \mathrm{mL}^{-1}$, and the cumulative release amount was close to $100 \%$ after $90 \mathrm{~h}$ measurements. Notably, no burst release of insulin occurred each time when the CNPs were placed back to $5.0 \mathrm{mg} \mathrm{mL}^{-1}$ glucose medium. The multiple and smoothly pulsed release behaviour indicates that the CNPs had potential to realize closeloop and consecutive insulin administration in response to the fluctuation of blood glucose concentration. These CNPs with $75 \%$ of P-2 content that can undergo the self-regulated glucoseswitchable release under physiological environment $(0.15 \mathrm{M}$ PBS, pH 7.4 and $37^{\circ} \mathrm{C}$ ) show promising application for potential clinical used glucose-responsive insulin delivery system.

In the previous work, it was found that $\mathrm{pH}$ value of environmental solution was rapidly dropped from 7.4 to 6.0 or lower with triggering the glucose-responsiveness of the nanocarriers formed from PBA-based polymers series at low salt environment (such as $0.01 \mathrm{M}$ and $0.03 \mathrm{M}$ ) or deionized water. In order to maintain the efficient glucose-responsiveness of those nanocarriers, the continuous adjusting $\mathrm{pH}$ value back to 7.4 by dropwise adding base into the environment solution was necessary. In this study, when the release of insulin from the CNPs with $75 \%$ of P-2 content was performed at the simulated physiological environment $\left(3.0 \mathrm{mg} \mathrm{mL}^{-1}\right.$ glucose, $0.15 \mathrm{M}$ PBS, $\mathrm{pH} 7.4$ and $37^{\circ} \mathrm{C}$ ), the corresponding $\mathrm{pH}$ value change was concurrently monitored (Fig. 7A). It was interestingly found that the $\mathrm{pH}$ value of the environment solution was almost kept stable at $\mathrm{pH} 7.4$ for $90 \mathrm{~h}$ measurements, which guarantees the successful performance of glucose-responsiveness of the CNPs without the aid of additional base. The buffer ability of such salt concentration endowed the whole glucose-responsive process with stable $\mathrm{pH}$ environment. This improved glucose-responsive insulin delivery system would better satisfy the physiological demand.

To further understand the probable reason of the selfregulated glucose-responsiveness of the CNPs, the secondary structure change of the CNPs with $75 \%$ weight fraction of P-2 during the intelligent response process at $3.0 \mathrm{mg} \mathrm{mL} \mathrm{m}^{-1}$ glucose, $0.15 \mathrm{M}$ PBS, pH 7.4 and $37{ }^{\circ} \mathrm{C}$ was monitored by CD technology. As shown in Fig. 7B, the contents of $\alpha$-helix and $\beta$ sheet in the whole secondary structure conformation did not have great change for $70 \mathrm{~h}$ measurements, and the sum of $\alpha$ helix and $\beta$-sheet content was kept above $50 \%$. Meanwhile, the
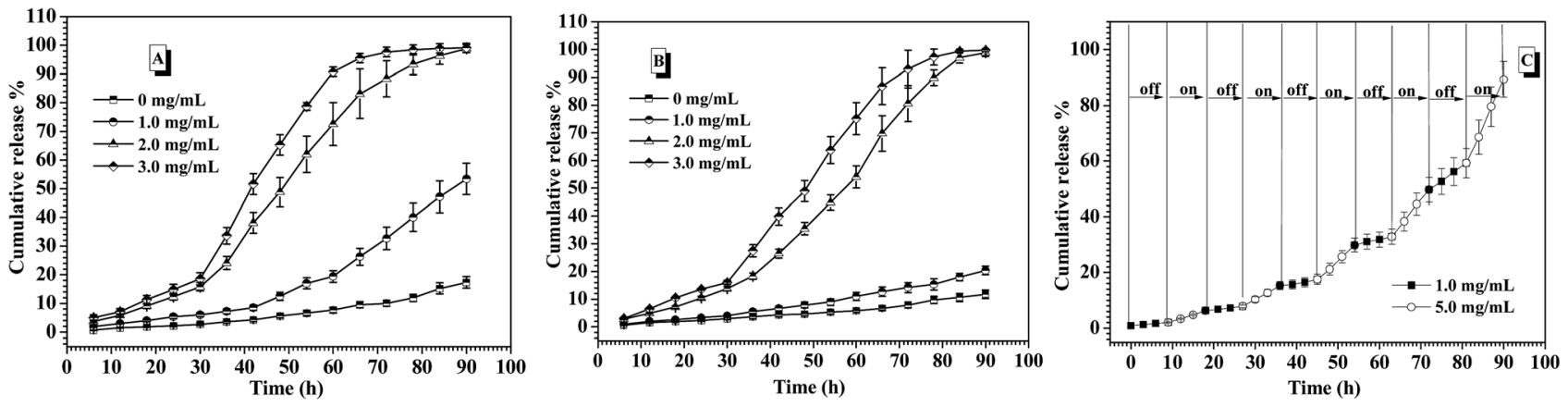

Fig. 6 Release profiles of FITC-insulin from the CNPs under varying concentrations of glucose at $0.15 \mathrm{M} \mathrm{PBS}, \mathrm{pH} 7.4$ and $37{ }^{\circ} \mathrm{C}$. (A) $50 \% \mathrm{P}-2$; (B) $75 \% \mathrm{P}-2$. (C) The glucose-responsive insulin release from CNPs with $75 \%$ content of P-2 with alternant glucose concentrations of 1.0 and 5.0 mg $\mathrm{mL}^{-1}$ at $0.15 \mathrm{M} \mathrm{PBS}, \mathrm{pH} 7.4$ and $37^{\circ} \mathrm{C}$. 

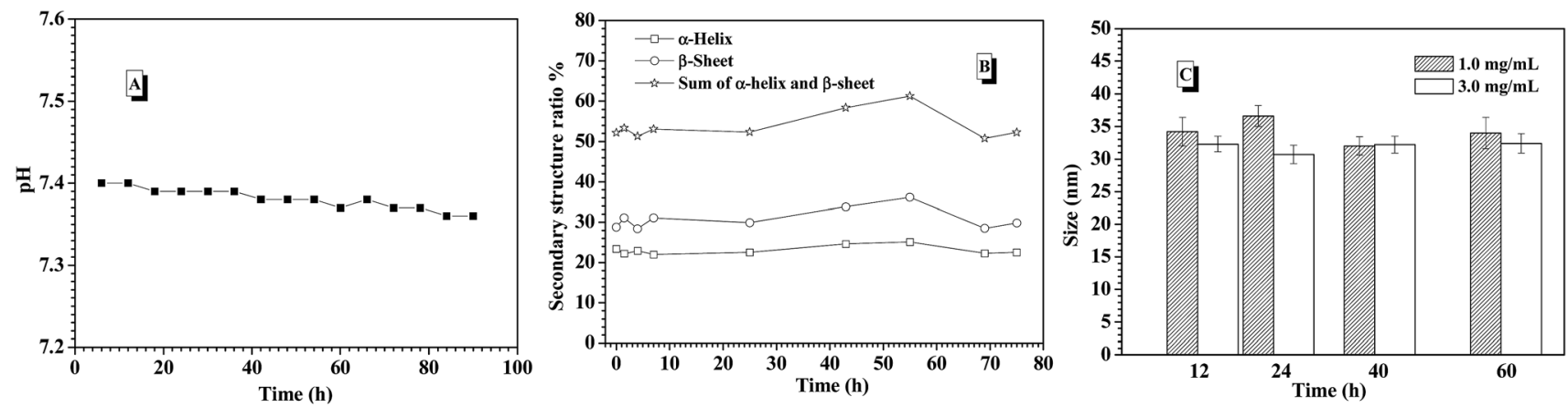

Fig. 7 (A) pH change of the environmental solution; (B) the secondary structure populations change of the CNPs with $75 \%$ content of P-2; (C) size change of the CNPs with $75 \%$ content of $\mathrm{P}-2$ during the process of insulin release under the stimuli of 1.0 and $3.0 \mathrm{mg} \mathrm{mL}^{-1} \mathrm{glucose}$ at $0.15 \mathrm{M}$ PBS, $\mathrm{pH} 7.4$ and $37^{\circ} \mathrm{C}$ for $90 \mathrm{~h}$ incubation.

sizes of CNPs were monitored by DLS under the stimuli of 1.0 and $3.0 \mathrm{mg} \mathrm{mL}^{-1}$ glucose at $0.15 \mathrm{M}$ PBS, $\mathrm{pH} 7.4$ and $37^{\circ} \mathrm{C}$ for $90 \mathrm{~h}$ incubation. As a result, only slight size fluctuation was observed in the range of 35 and $40 \mathrm{~nm}$ (Fig. 7C). This indicates that the dominant framework constructed by P-2 in the CNPs was well maintained, and the chemical structure change of P-1 under the stimuli of glucose didn't bring great impact on the whole skeleton of the CNPs in the glucose response process.

Combined with the above experimental results, the salttolerance of CNPs with $75 \%$ content of P-2 and their selfregulated glucose-responsiveness were tried to deduce as shown in Fig. 8. Besides the hydrophobic interaction of the amphiphilic copolymers P-1 and P-2, the hydrogen bonding, which maintained the secondary structures of the hydrophobic polypeptide block, further supported the whole CNPs. The combination of hydrophobic interaction with hydrogen bonding significantly enhanced the stability of the complex nanoparticles in salt solution. The higher content of P-2 in CNPs, the more contribution from hydrogen bonding to maintain the nanoparticles, and the more stable the CNPs in 0.15 PBS. The polypeptides formed one solid skeleton in the CNPs to sustain the whole nanoparticles and guard glucose-responsive segments of P-1.

This special hydrophobic structure improved the glucosesensitive capacity of CNPs to distinguish normoglycemia and hyperglycemia, trying to avoid the release behavior of insulin at normal or low glucose concentration. Although the insulin release was induced by glucose molecules reacting with phenylboronate ester units of hydrophobic blocks, similarly to the

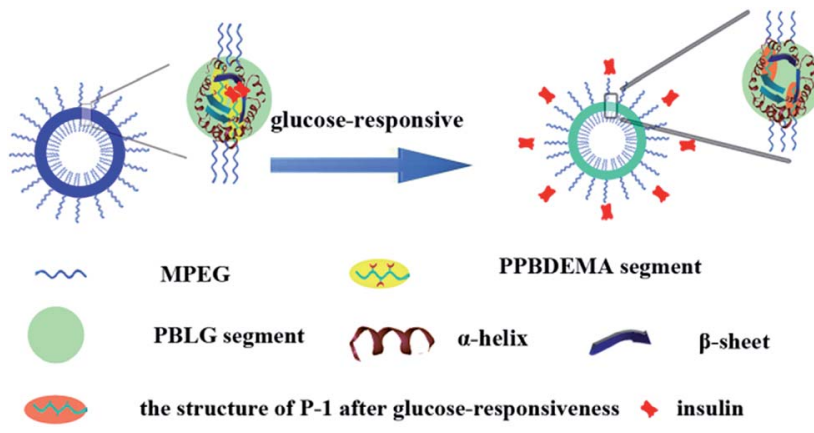

Fig. 8 Illustration of CNPs' structure and their glucose responsiveness. previous work, ${ }^{37,38}$ the hydrophobic frameworks of the CNPs were completely retained by the dominant polypeptides in the whole process of glucose response. This was greatly different from the reported nanoparticles with only phenylboronate ester as hydrophobic core, in which the hydrophobic core would be rapidly destroyed with response to glucose molecules. This firmly hydrophobic skeleton allows the self-regulated release of insulin with glucose concentration fluctuating.

\section{Cell toxicity assays of the CNPs}

In vitro cytotoxicity assays of the CNPs with $75 \%$ content of P-2 were performed using familiar NIH 3T3 mouse fibroblast cells and analyzed by MTS assay (Fig. 9). For all of the culture, the relative cell proliferation rates were close to $100 \%$ for $24 \mathrm{~h}$, irrespective of the CNPs' concentration. The NIH3T3 cell viability was still maintained more than $80 \%$ after 48 and $72 \mathrm{~h}$ cultivation as the nanoparticle concentration increasing from 25 to $500 \mathrm{mg} \mathrm{\textrm {L } ^ { - 1 }}$, demonstrating that the CNPs did not negatively impact cell proliferation. Compared to the nanoparticles formed from only P-1 (Fig. S13†), the CNPs exhibited higher cell viability in the experimental range, suggesting that the introduction of polypeptide segment successfully enhanced biocompatibility of the nanocarriers.

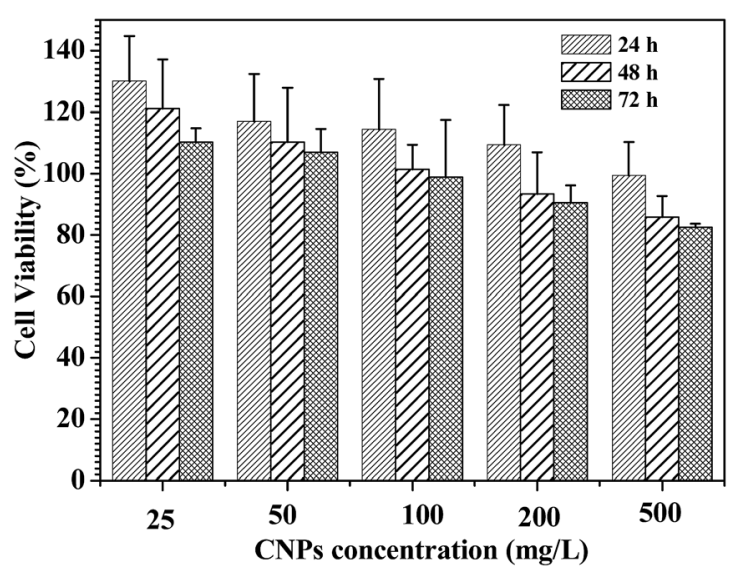

Fig. 9 Cell viability assay in NIH3T3 mouse fibroblast cell. The cells were treated with the CNPs with $75 \%$ content of $\mathrm{P}-2$ at various concentrations at $37{ }^{\circ} \mathrm{C}$ for 24,48 and $72 \mathrm{~h}$, respectively. 


\section{Conclusions}

In summary, glucose-responsive CNPs were prepared via coassembly of the amphiphilic polymers MPEG- $b$-PPBDEMA and MPEG- $b$-PBLG. Due to the introduction of hierarchical PBLG blocks, the stability of the whole CNPs was significantly strengthened by hydrogen bonding of polypeptide block on the basis of hydrophobic aggregation of the hydrophobic blocks. As a result, the salt tolerance of the CNPs was concomitantly enhanced in 0.15 M PBS with increasing the weight fraction of MPEG- $b$-PBLG in CNPs. When MPEG- $b$-PBLG content reached $75 \%$, the solid skeleton formed by the polypeptides in the CNPs sustained the whole nanoparticles in the process of glucose response, and greatly improved the glucose-sensitive capacity of CNPs to distinguish normoglycemia and hyperglycemia under physiological condition (0.15 M PBS, pH 7.4 and $37^{\circ} \mathrm{C}$ ), efficiently avoiding the release behavior of insulin at normal or low glucose concentration. This kind of intelligent nanoparticles may be a promising glucose-responsive nanocarrier and find applications in insulin delivery. A further study on animal models is underway in our laboratory.

\section{Acknowledgements}

This work was supported by National Natural Science Foundation of China (NSFC, Grant No. 21174013; 21374005), the New Century of Ministry of Education (NCET-12-0754), Beijing National Laboratory for Molecular Sciences (BNLMS20150127).

\section{Notes and references}

1 American Diabetes Association, Diabetes Care, 2012, 35, S11.

2 D. R. Owens, B. Zinman and G. B. Bolli, Lancet, 2001, 358, 739.

3 R. Ma and L. Shi, Polym. Chem., 2014, 5, 1503.

4 W. Wu and S. Zhou, Macromol. Biosci., 2013, 11, 1464.

5 R. Mo, T. Jiang, J. Di, W. Tai and Z. Gu, Chem. Soc. Rev., 2014, 43, 3595.

6 I. Otsuka, T. Hongo, H. Nakade, A. Narumi, R. Sakai, T. Satoh, H. Kaga and T. Kakuchi, Macromolecules, 2007, 40, 8930.

7 W. Qi, X. Yan, J. Fei, A. Wang, Y. Cui and J. Li, Biomaterials, 2009, 30, 2799.

8 T. Ye, X. Bai, X. Jiang, Q. Wu, S. Chen, A. Qu, J. Huang, J. Shen and W. Wu, Polym. Chem., 2016, 7, 2847.

9 A. Matsumoto, T. Ishii, J. Nishida, H. Matsumoto, K. Kataoka and Y. Miyahara, Angew. Chem., Int. Ed., 2012, 124, 2166.

10 D. Mandal, S. K. Mandal, M. Ghosh and P. K. Das, Chem.Eur. J., 2015, 21, 12042.

11 X. Zou, X. Zhao and L. Ye, RSC Adv., 2015, 5, 96230.

12 W. Yuan, L. Li and H. Zou, RSC Adv., 2015, 5, 80264.

13 Q. Guo, Z. Wu, X. Zhang, L. Sun and C. Li, Soft Matter, 2014, 10, 911.

14 H. Guo, H. Li, L. Ling, B. Wang, Q. Guo, Y. Gu and C. Li, Polym. Chem., 2016, 7, 3189.

15 D. Shi, M. Ran, L. Zhang, H. Huang, X. Li, M. Chen and M. Akashi, ACS Appl. Mater. Interfaces, 2016, 8, 13688.
16 H. Kim, Y. J. Kang, E. S. Jeong, S. Kang and K. T. Kim, ACS Macro Lett., 2012, 1, 1194.

17 I. Dasgupta, E. A. Tanifum, M. Srivastava, S. S. Phatak, C. N. Cavasotto, M. Analoui and A. Annapragada, PLoS One, 2012, 7(1), e29585.

18 M. Zhang, W. Wang, R. Xie, X. J. Ju, L. Liu, Y. Y. Gu and L. Y. Chu, Soft Matter, 2013, 9, 4150.

19 H. Yang, C. Zhang, C. Li, Y. Liu, Y. An, R. Ma and L. Shi, Biomacromolecules, 2015, 16, 1372.

20 Q. Guo, T. Zhang, J. An, Z. Wu, Y. Zhao, X. Dai and X. Zhang, Biomacromolecules, 2015, 16, 3345.

21 J. Liang, Y. Ma, S. Sims and L. Wu, J. Mater. Chem. B., 2015, 3, 1281.

22 Z. Zou, D. He, L. Cai, X. He, K. Wang, X. Yang, L. Li, S. Li and X. Su, ACS Appl. Mater. Interfaces, 2016, 8, 8358.

23 A. Matsumoto, S. Ikeda, A. Karada and K. Kataoka, Biomacromolecules, 2003, 4, 1410.

24 A. Matsumoto, R. Yoshida and K. Kataoka, Biomacromolecules, 2004, 5, 1038.

25 A. Matsumoto, K. Yamamoto, R. Yoshida, K. Kataoka, T. Aoyagi and Y. Miyahara, Chem. Commun., 2010, 46, 2203.

26 A. Matsumoto, T. Ishii, J. Nishida, H. Matsumoto, K. Kataoka and Y. Miyahara, Angew. Chem., Int. Ed., 2012, 51, 2124.

27 C. Cheng, X. G. Zhang, J. X. Xiang, Y. X. Wang, C. Zheng, Z. T. Lu and C. X. Li, Soft Matter, 2012, 8, 765.

28 C. Cheng, X. Zhang, Y. Wang, L. Sun and C. Li, New J. Chem., 2012, 36, 1413.

29 Y. Kotsuchibashi, R. V. C. Agustin, J. Y. Lu, D. G. Hall and R. Narain, ACS Macro Lett., 2013, 2, 260.

30 T. Hoare and R. Pelton, Macromolecules, 2007, 40, 670.

31 B. L. Wang, R. J. Ma, G. Liu, Y. Li, X. J. Liu, Y. L. An and L. Q. Shi, Langmuir, 2009, 25, 12522.

32 B. L. Wang, R. J. Ma, G. Liu, Y. Li, X. J. Liu, Y. H. Gao, J. Y. Shen, Y. L. An and L. Q. Shi, Macromol. Rapid Commun., 2010, 31, 1628.

33 R. J. Ma, H. Yang, Z. Li, G. Liu, X. C. Sun, X. J. Liu, Y. L. An and L. Q. Shi, Biomacromolecules, 2012, 13, 3409.

34 H. Yang, X. Sun, G. Liu, R. Ma, Z. Li, Y. An and L. Shi, Soft Matter, 2013, 9, 8589.

35 L. Sun, X. Zhang, C. Zheng, Z. Wu, X. Xia and C. Li, RSC Adv., 2012, 2, 9904.

36 A. Matsumoto, K. Yamamoto, R. Yoshida, K. Kataoka, T. Aoyagi and Y. Miyahara, Chem. Commun., 2010, 46, 2203.

37 Y. Yao, X. M. Wang, T. W. Tan and J. Yang, Soft Matter, 2011, 7, 7948.

38 Y. Yao, L. Y. Zhao, J. J. Yang and J. Yang, Biomacromolecules, 2012, 13, 1837.

39 Y. Yao, H. Shen, G. Zhang, J. Yang and X. Jin, J. Colloid Interface Sci., 2014, 431, 216.

40 L. Zhao, X. Zhang, Y. Yao, C. Yu and J. Yang, Macromol. Chem. Phys., 2014, 215, 1609.

41 G. Zhang, X. Zhang, H. Shen, J. J. Yang and J. Yang, RSC Adv., 2014, 4, 49964.

42 X. Zhang, L. Zhao, J. J. Yang and J. Yang, RSC Adv., 2016, 6, 21486.

43 C. Deng, J. Wu, R. Cheng, F. Meng, H. A. Klok and Z. Zhong, Prog. Polym. Sci., 2014, 39, 330. 
44 M. A. Quadir, M. Martin and P. T. Hammond, Chem. Mater., 2014, 26, 461.

45 J. Fan, J. Zou, X. He, F. Zhang, S. Zhang, J. E. Raymond and K. L. Wooley, Chem. Sci., 2014, 5, 141.

46 J. Ding, C. Li, Y. Zhang, W. Xu, J. Wang and X. Chen, Acta Biomater., 2015, 11, 346.

47 Y. Shen, X. Fu, W. Fu and Z. Li, Chem. Soc. Rev., 2015, 44, 612.

48 L. Y. Lin, P. C. Huang, D. J. Yang, J. Y. Gao and J. L. Hong, Polym. Chem., 2016, 7, 153.

49 Y. Liu, P. Chen and Z. Li, Macromol. Rapid Commun., 2012, 33, 287.

50 L. Zhao, J. Ding, C. Xiao, P. He, Z. Tang, X. Pang, X. Zhuang and X. Chen, J. Mater. Chem., 2012, 22, 12319.

51 G. Liu, R. Ma, J. Ren, Z. Li, H. Zhang, Z. Zhang, Y. An and L. Shi, Soft Matter, 2013, 9, 1636.

52 H. Yang, R. Ma, J. Yue, C. Li, Y. Liu, Y. An and L. Shi, Polym. Chem., 2015, 6, 3837.

53 M. Danial and H. A. Klok, Chem. Soc. Rev., 2010, 39, 3541.

54 D. W. P. M. Löwik, E. H. P. Leunissen, M. van den Heuvel, M. B. Hansen and J. C. M. van Hest, Chem. Soc. Rev., 2010, 39, 3394 .
55 N. T. Ross, W. P. Katt and A. D. Hamilton, Philos. Trans. R. Soc., A, 2010, 368, 989.

56 Z. B. Li, E. Kesselman, Y. Talmon, M. A. Hillmyer and T. P. Lodge, Science, 2004, 306, 98.

57 I. K. Voets, P. M. Moll, A. Aqil, C. Jerome, C. Detrembleur, P. de Waard, A. de Keizer and M. Stuart, J. Phys. Chem. B, 2008, 112, 10833.

58 W. H. Daly and D. Poché, Tetrahedron Lett., 1988, 29(46), 5859.

59 M. G. Li, W. Lu, L. J. Wang, C. X. Zhang, X. Q. Wang, A. P. Zheng and Q. Zhang, Int. J. Pharm., 2007, 329, 182.

60 S. W. Kuo, H. F. Lee, W. J. Huang, K. U. Jeong and F. C. Chang, Macromolecules, 2009, 42, 1619.

61 A. Aggeli, M. Bell, N. Boden, J. N. Kenn, P. F. Knowles, T. C. B. Mcleish, M. Pitkeathly and S. E. Radford, Nature, 1997, 386, 259.

62 V. K. Kotharangannagari, A. Sanchez-Ferrer, J. Ruokolainen and R. Mezzenga, Macromolecules, 2012, 45, 1982. 